\title{
Intervenções urbanas, usos e ocupações de espaços na região central de Belo Horizonte
}

\author{
Urban interventions, usage and occupation of \\ spaces in the central region of Belo Horizonte
}

\author{
Juliana Gonzaga Jayme* \\ Eveline Trevisan**
}

\begin{abstract}
Resumo: Apesar de jovem (inaugurada em 1897) Belo Horizonte passou por um relativo processo de esvaziamento de seu centro histórico com a demolição de alguns edifícios, o deslocamento das moradias de classe média para outras regiões, a diminuição de áreas de espaço público de convivência e da presença da elite nessa região. Como em diversas cidades, esse processo mobilizou agentes públicos e iniciativa privada na elaboração de projetos de requalificação urbana voltados para sua área central. A proposta deste trabalho é refletir sobre a forma como esses projetos vêm sendo implementados pelo poder público e a região requalificada vem sendo apropriada pelos diferentes atores. Nossa hipótese é de que os processos de requalificação urbana em Belo Horizonte não devem ser pensados como intervenções voltadas apenas para o mercado, o entretenimento e o consumo cultural, numa palavra, a gentrificação.
\end{abstract}

Palavras-Chave: Belo Horizonte; região central; gentrificação; espaço público

\begin{abstract}
Despite its youth (founded 1897) Belo Horizonte has witnessed a "relative" process of emptying the historic center with the demolition of some buildings, the displacement of middle-class to other regions, the reduction of areas of public space for coexistence and the presence of the elite in this region. Like in several cities, this process has mobilized the public and the private sector in the development of urban regeneration projects in their centers. The purpose of this paper is to analyze how these projects are being implemented by the government, as well as how the region has been appropriated by these actors. Our hypothesis is that the processes of urban regeneration in Belo Horizonte are not a gentrification, which would mean interventions directed only to the market, to entertainment and cultural consumption.
\end{abstract}

Keywords: Belo Horizonte; downtown; gentrification; public space

* Doutora em Ciências Sociais pela Unicamp, professora e pesquisadora do Programa de Pós-graduação em Ciências Sociais da PUC Minas. <julianajayme@pucminas.br>.

**Mestre em Ciências Sociais pela PUC Minas.<eveline@pbh.gov.br>.

\begin{tabular}{|l|l|l|l|l|l|}
\hline Civitas & Porto Alegre & v. 12 & n. 2 & p. 359-377 & maio-ago. 2012 \\
\hline
\end{tabular}


Apesar de jovem, Belo Horizonte ${ }^{1}$ - como a maioria das cidades brasileiras - a partir do final dos anos 1970 passou por um "relativo" processo de esvaziamento de seu centro histórico, com a demolição de alguns edifícios, o deslocamento das moradias de classe média para outras regiões, a diminuição de áreas de espaço público de convivência, a transferência do comércio voltado para os estratos mais altos, enfim, o surgimento de novas centralidades. Como na maior parte das grandes cidades, a partir do final dos anos 1980 e início dos 1990, o centro torna a ser valorizado, agora por sua importância histórica, mobilizando agentes públicos e sociedade civil na elaboração de projetos de requalificação urbana - com a restauração dos edifícios e das ruas - para que a região seja (re)apropriada pela população.

Este artigo pretende refletir sobre como esses projetos vêm sendo implementados pelo poder público e como a população vem se apropriando desse centro requalificado em Belo Horizonte. Nossa hipótese é que, aqui, essas intervenções estão sendo estabelecidas numa direção diferente dos processos de gentrificação comuns no Brasil e em outros países. Entendendo que não há consenso em torno da ideia de gentrificação, ${ }^{2} \mathrm{o}$ termo é usado aqui para se referir às intervenções urbanas realizadas nos centros das cidades, com vistas à retomada desses locais como lugar de consumo (cultural) e entretenimento, transformando-os em museus abertos e belos, onde parece não caber mais a população pobre que se apropriava daquele lugar, que é substituída pelas camadas médias e altas, seja para morar, seja para consumir o espaço ${ }^{3}$ e/ou no espaço. (Zukin, 2000; Leite, 2002; Criekingen, 2006; Smith, 2006; Arantes, 2009; Rubino, 2009; Frúgoli Jr. e Sclair, 2009).

Antes de discutir essa hipótese, porém, far-se-á aqui um pequeno histórico de Belo Horizonte, no sentido de apresentá-la ao leitor, além de uma breve descrição sobre suas transformações até a década de 2000, quando os projetos de requalificação urbana para a retomada do Centro da cidade começam a ser levados a cabo.

\section{Belo Horizonte e sua área central}

Capital de Minas Gerais, Belo Horizonte foi a primeira cidade planejada da República no Brasil e sua planta, elaborada pelo engenheiro Aarão Reis previa uma zona urbana (circunscrita pela Avenida do Contorno), uma suburbana e uma rural. Por ter sido planejada para simbolizar a ideologia

\footnotetext{
Belo Horizonte foi inaugurada em dezembro de 1897.

Aliás, não há nem em relação ao uso do neologismo em português.

Zukin (2000).
} 
positivista e a modernidade, sua arquitetura foi marcada por ruas e avenidas largas e retas. Inspirada na Paris de Haussman e na Washington de L'Énfant, as cidades modernas, belas e, sobretudo, higiênicas ou saneadas de então, o mapa da zona urbana de Belo Horizonte - que corresponde atualmente à área central - é como que traçado com régua, com ruas na malha ortogonal e avenidas na diagonal. Talvez Rua, poema de Carlos Drummond de Andrade, represente essa cidade melhor do que qualquer mapa:

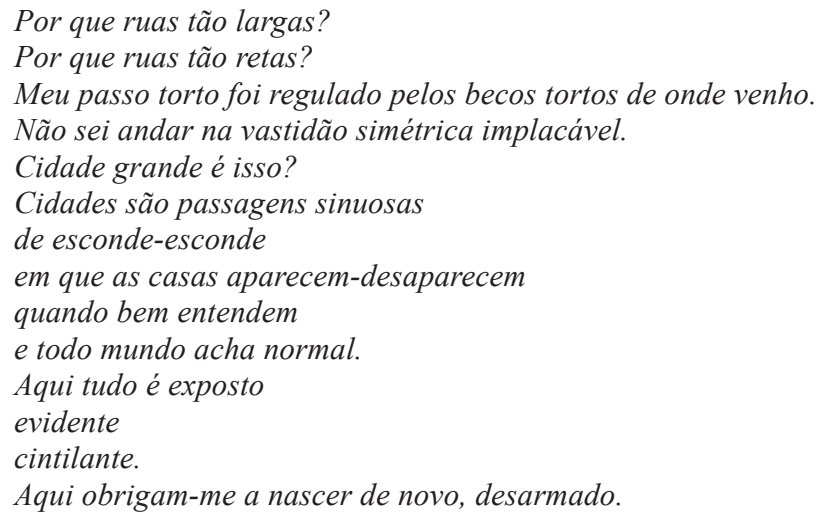

Para Benjamin (1985), ao expulsar para a periferia os pobres parisienses, Haussman contribui para que estes estranhem sua própria cidade. Parece que Drummond nunca se sentiu realmente em casa nessa Belo Horizonte que o fazia se sentir desarmado (vigiado, talvez). Por outro lado, provavelmente o poeta percebesse também certo frescor daquela cidade que se pretendia moderna e organizada, embora na época em que lá viveu o limite da cidade planejada já estivesse se rompendo.

Desde o final do século 19 e ao longo do 20, quase todas as grandes cidades sofreram transformações. Apesar de sua juventude, Belo Horizonte também teve seu núcleo central modificado logo no início do século 20 . Celina Lemos (2010) sistematiza em termos históricos a produção e as transformações do espaço urbano na Capital em cinco momentos principais: a implantação do projeto de Aarão Reis; a consolidação do plano e a formação das paisagens; a busca pela modernização e as primeiras legislações de gestão dos espaços; a conurbação do Centro e as consequentes expansões e/ou extensões; os incontroláveis processos de demolição e a renovação do centro tradicional. É possível acrescentar à sistematização da autora um novo momento, mais atual, de execução dos projetos e programas de revitalização urbana nos anos 2000 . 
Na década de 1920, a Avenida do Contorno deixava de ser o limite da zona urbana da cidade para delimitar apenas sua área central. Entre os anos 1930 e 1950, as intervenções físicas em Belo Horizonte tinham por objetivo conformar uma atraente paisagem urbana e iniciava-se um processo de verticalização da área central.

O desenvolvimento econômico e a intensificação do processo de urbanização da capital caracterizaram o período pós Segunda Guerra e, em 50 anos, Belo Horizonte se transformou na terceira maior cidade do Brasil. De acordo com Lemos (2010), as transformações pelas quais a cidade passou, com uma série de demolições e renovações, determinaram um novo ambiente urbano com uma maior concentração demográfica, principalmente no centro. Nos anos 1950, a região ainda era um lugar heterogêneo. Ao comentar sobre essa época, Andrade e Jayme (2011, p. 07) afirmam:

Se antes a Rua da Bahia era o lugar dos teatros, cinemas, cafés e lojas, agora a Avenida Afonso Pena abrigava cada vez maior variedade de serviços e atividades e atraía mais frequentadores, seja nas Casas de Chá e cafés, seja nas lojas, nos cinemas e no footing que espacializava a exclusão. [...] De um lado da Avenida Afonso Pena ficavam os negros e as empregadas domésticas e do outro lado a elite que residia na área central.

A década de 1960 foi marcada por intervenções físicas que responderam, basicamente, aos interesses do capital e do automóvel. As ruas do centro, que até então abrigavam uma sociabilidade marcada pelo andar à toa, a pé, foram tomadas pelos carros, se tornando cada vez mais lugares de passagem. A cidade perdeu muito de seu patrimônio edificado e redefiniu áreas e funções descaracterizando, muitas vezes, edifícios e áreas públicas. No caso do centro, já em 1970, predominava a homogeneização da paisagem urbana e o aparecimento de novas centralidades fez com que a região fosse abandonada pelos estratos médios e altos, se tornando cada vez mais um local de trânsito intenso de veículos e pedestres. Nessa época o lugar já é representado como degradado e perigoso (Arroyo, 2004; Moreira, 2008; Lemos, 2010; Andrade e Jayme, 2011).

Nos anos 1980, embora o centro de Belo Horizonte ainda mantivesse certa função de centralidade, já a dividia com outras áreas. A região da Savassi, por exemplo, era apropriada pelos estratos médios e altos como fora a região central dos anos 1950. Como na maioria das grandes cidades brasileiras, o centro parecia ter perdido sua importância simbólica. Mas foi também nessa década, em 1986, que, em Belo Horizonte, o Conselho Deliberativo 
do Patrimônio Cultural foi regulamentado, com o objetivo de organizar a proteção do patrimônio cultural da cidade. No final da década a Prefeitura de Belo Horizonte se mobilizou em torno de projetos urbanos voltados para a recuperação da Área Central, quando essa perspectiva de intervenção passou a adquirir contornos mais nítidos e maior visibilidade, com a disseminação do discurso da importância da região para a história e a memória da cidade e da necessidade de melhoria das condições de seus espaços físicos, estabelecendose forte confluência entre as ideias de valorização simbólica e de recuperação física de um espaço considerado degradado (Moreira, 2008).

Nos anos 1990, acompanhando as tendências internacionais de revalorização dos Centros Históricos, em Belo Horizonte - como em outras cidades brasileiras - os projetos de intervenção, física e simbólica, na região central se afirmaram de forma mais sistemática e concreta. Nesse período, a região passou a ser objeto de diferentes diagnósticos, sendo que mereceu destaque o concurso nacional BH-Centro (1990), promovido pela Prefeitura de Belo Horizonte, que visava à seleção de ideias para revitalização de algumas áreas de maior valor simbólico no centro. Na década seguinte, dois programas municipais mereceram destaque: Projeto 4 Estações, de 2000 e o Programa Centro Vivo, de 2004.

O Projeto 4 Estações foi decorrente de um concurso elaborado pela Prefeitura de Belo Horizonte em parceria com o IAB/MG, ${ }^{4}$ que selecionou equipes para desenvolvimento de projetos, em três áreas da região central (Hipercentro, ${ }^{5}$ Savassi e Área Hospitalar), vinculados a intervenções de melhoria de circulação e do transporte coletivo.

O Programa Centro Vivo, ainda em vigor, se propõe à recuperação de setores distintos da vida urbana: da economia, inclusão social, mobilidade e segurança pública até sua chamada requalificação urbanística e ambiental.

O Programa Centro Vivo é um conjunto de obras e projetos sociais da Prefeitura que prevê a requalificação de espaços coletivos da área central de Belo Horizonte. A iniciativa veio para reforçar o centro como região simbólica da cidade, valorizando a diversidade de suas atividades e consolidando-o como local de encontro de todos. ${ }^{6}$

Como se vê pelo texto do site da Prefeitura Municipal, a ação é sustentada pelo discurso usual de preservação e de retomada da região como lugar aberto

4 IAB (Instituto dos Arquitetos do Brasil) secção Minas Gerais.

5 O hipercentro é considerado a área delimitada pelas Avenidas Bias Fortes, Praça Raul Soares, Avenida Álvares Cabral, Rua dos Timbiras, Parque Municipal, Avenida Francisco Sales, Rua Itambé, Rua Sapucaí, Avenida do Contorno e Rodoviária.

$6<$ http://portalpbh.pbh.gov.br>. Acesso em: 30 jun. 2011. 
a todos, espaço da diversidade. Essas são as principais características do espaço público que, exatamente por tais aspectos, pode ser também o lugar do conflito. Será que essa dimensão é pensada da perspectiva dos técnicos formuladores do projeto e do próprio poder público? O Programa Centro Vivo é amplo e já vem sendo implantado há oito anos e, por isso mesmo, não é possível, no escopo de um artigo, abordá-lo como um todo. Aqui discutiremos a área requalificada do chamado Baixo Centro. ${ }^{7}$

\section{O Baixo Centro requalificado: breve descrição}

O Baixo Centro teve várias intervenções urbanas ao longo do ano 2000. Essa área, cuja delimitação é mais simbólica do que propriamente física, está polarizada pela Praça Rui Barbosa e pela recente intervenção denominada Boulevard Arrudas, indo da Serraria Souza Pinto até o edifício do antigo 104 Tecidos, incluindo, ainda, equipamentos como o Viaduto de Santa Tereza, a Casa do Conde de Santa Marinha, o Museu de Artes e Ofícios e os trechos das ruas Aarão Reis, Caetés, Tupinambás, Guaicurus e Santos Dumont.

A Praça Rui Barbosa - conhecida como Praça da Estação - começou a ser construída em 1904 e passou por várias transformações ao longo da história da cidade. Nos anos 1920 recebeu jardins em estilo francês, com canteiros geométricos, baixa vegetação e espelhos d'água. No final dos 1950 teve seus passeios recortados e as árvores derrubadas. Em 1965, com a duplicação da Avenida dos Andradas, que corta a área da Praça ao meio, perdeu parte dos jardins, um lago e as esculturas. A partir da década de 1980 a esplanada em frente à Estação Ferroviária passou a ser utilizada como estacionamento de veículos durante o dia. Em 1995, tem início o processo de recuperação dos jardins da Praça. Em 2006 foi inaugurado o Museu de Artes e Ofícios de Belo Horizonte, instalado no prédio da Estação Ferroviária. ${ }^{8}$ Em 2007, com a implantação do Boulevard Arrudas, ${ }^{9}$ a Praça teve sua dimensão e desenho originais recuperados, o Ribeirão Arrudas foi tamponado, os jardins foram

\footnotetext{
Essa área, segundo a pouca bibliografia disponível, começou a ser caracterizada sob essa nomenclatura, a partir de meados do século 20 , quando se acentuou o processo de distinção socioespacial no interior do centro da cidade. Assim, a área localizada mais abaixo do centro, ou seja, às margens do Ribeirão Arrudas e em contraposição à Praça da Liberdade (porção mais alta da área central), recebeu a instalação de grandes equipamentos como estação ferroviária, rodoviária, galpões, fábricas, garagens e um comércio mais popular.

8 Parceria do Instituto Cultural Flávio Gutierrez, com o Ministério da Cultura e a Companhia Brasileira de Trens Urbanos (CBTU).

9 Projeto que faz parte de uma intervenção mais ampla que visa estabelecer a ligação entre o hipercentro de Belo Horizonte e a região norte da cidade, chegando ao Aeroporto Internacional, a Linha Verde. A Prefeitura de Belo Horizonte foi responsável pela elaboração dos projetos nos limites do município, enquanto o Governo do Estado se responsabilizou pela implantação das obras. O trecho inserido na área central da cidade recebeu o nome de Boulevard Arrudas.
} 
restaurados, a iluminação pública trocada, e a largura das calçadas aumentada em três vezes.

O Viaduto de Santa Teresa foi inaugurado em 1929 e em 1999 teve sua estrutura original recuperada e, debaixo dela, próximo à Serraria Souza Pinto, foi feito um palco, pista de dança, arquibancada e bar e, próximo à cabeceira da Rua da Bahia, um espaço destinado à exposição de esculturas e uma sala de multiuso.

Erguida em 1912, a Serraria Souza Pinto foi restaurada em 1997 para a realização de eventos. Em dezembro de 1998 tornou-se um espaço para espetáculos, feiras, congressos, eventos sociais, comerciais e técnicocientíficos.

O prédio do 104 Tecidos $^{10}$ foi inaugurado em 1908 para abrigar a Companhia Industrial Bello Horizonte, considerada a primeira grande indústria da capital mineira. A partir da década de 1930, foi ocupado por outras companhias têxteis e ficou popularmente conhecido como 104 Tecidos. Ao longo dos anos, o imóvel passou por inúmeras reformas que descaracterizaram o projeto original. Restaurado na década de 2000, o edifício abriga, desde 2009, o Espaço CentoeQuatro, que é a um só tempo, café, cinema e galeria". ${ }^{11}$

A Casa do Conde de Santa Marinha foi construída em 1896 para servir de residência ao construtor e industrial Antônio Teixeira Rodrigues, conde de Santa Marinha, que trabalhou na edificação da capital mineira. O imóvel e os galpões do seu entorno abrigavam a família do conde e também suas atividades comerciais. Entre 1957 e $1996^{12}$ funcionou ali o Museu Ferroviário. Atualmente, o complexo é ocupado pela Fundação Nacional de Artes (Funarte). ${ }^{13}$

Todas as vias integrantes da área aqui discutida fazem parte do Programa Caminhos da Cidade, que prevê o reordenamento dos espaços das vias visando à melhoria do caminhamento de pedestres. O programa prevê ampliação das calçadas, implantação das normas de acessibilidade, instalação de novo paisagismo, iluminação e novo mobiliário urbano, além de desobstrução e ordenamento das fachadas.

\section{Intervenções urbanas: contextualizando as discussões}

Como se sabe, a (re)valorização dos centros das grandes cidades se dá devido à importância conferida ao consumo da história e, por isso, é realizada, em geral, por meio de intervenções de cunho controlador e higienista que

\footnotetext{
$10<\mathrm{http} / / /$ www.centoequatro.org/o-predio $>$.

$11<\mathrm{http}: / /$ www.centoequatro.org $>$.

${ }^{12}$ Quando a Rede Ferroviária Federal foi desestatizada.

$13<$ http://portal6.pbh.gov.br/dom/iniciaEdicao.do?method=DetalheArtigo\&pk=989520>.
} 
buscam adequar as cidades às demandas econômicas internacionais, desse modo, há uma apropriação cultural das cidades (melhor, das suas imagens) com vistas a dar novos sentidos ao passado ${ }^{14} \mathrm{e}$, como apontam Certeau e Giard (2003), não exatamente a qualquer passado, mas àquele que pode ser visto como patrimônio.

No Brasil, em algumas capitais, tem havido projetos de requalificação urbana desde o início dos anos 1990, geralmente a partir de parcerias entre o poder público e a iniciativa privada e, pelas análises acerca desses casos - geralmente de cidades turísticas do Nordeste, como Salvador, Recife e Fortaleza -, percebe-se, na maior parte das vezes, que tais intervenções apresentaram características fortemente higienistas e podem ser pensadas como gentrificadoras, ${ }^{15}$ mesmo que aqui não se perceba a gentrificação residencial, mas a de consumo, para falar com Criekigen (2003) ou a "gentrificação sem passado" mencionada por Héléne Rivière d'Arc (2006). A verdade é que o retorno aos centros pelas camadas médias não teve, nessas capitais, "vida longa", talvez porque aqui as intervenções tenham sido feitas de modo muito artificializado e com uma prática muito distante do discurso, que sempre teve como mote uma devolução da área central a toda a população, retomando o seu uso tradicional de espaço público heterogêneo. Os visitantes, porém, acabaram por frequentar esses locais de forma descontínua e os antigos usuários (moradores e/ou trabalhadores) tiveram dificuldade de se manter nos centros gentrificados.

Quanto à terminologia empregada para designar intervenções em áreas urbanas representadas como degradadas, um leque de termos vem sendo utilizado. Ainda que não haja um consenso sobre qual seria o mais adequado, parece importante apontar aqui algumas considerações.

$\mathrm{O}$ termo revitalização tem sido amplamente usado na bibliografia sobre o tema, embora haja discordância sobre a pertinência do seu uso. Duarte (2005) argumenta que sua etimologia sugere uma visão preconceituosa e errônea da área de intervenção, já que esses centros não teriam perdido sua vitalidade. O autor faz um "inventário" das terminologias que vêm sendo empregadas: a renovação denominaria um processo de substituição das formas urbanas existentes por outras modernas. Pode ser pontual. A requalificação englobaria processos de alteração em uma área urbana com o fim de conferir-lhe nova função. Já a reabilitação constituiria um processo integrado de recuperação de uma área urbana que se pretende salvaguardar, implicando o restauro de

\footnotetext{
${ }_{14}$ Sobre isso ver Zukin (2000); Leite (2002); Rubino (2009). Para o caso de Belo Horizonte conferir Andrade e Jayme (2011).

${ }^{15}$ Ver, entre outros, Leite (2002); Barreira (2010); Rivière d'Arc (2006).
} 
edifícios, a revitalização do tecido econômico e social e a retomada do uso residencial.

O termo revitalização, mesmo que seja considerado inadequado por vários autores, é bastante utilizado no Brasil para designar as intervenções urbanas voltadas para a recuperação de áreas centrais. De acordo com Silvana Rubino (2008) o termo se vulgarizou tanto que perdeu seu sentido original, que não remeteria a um lugar desvitalizado. Foi empregado pela Unesco, em 1962, para se referir a ações cidadãs que paralisassem as destruições do patrimônio. "Mas, foi na Conferência de Nairobi, de 1976, que o termo ganhou contornos mais nítidos, como parte de uma ação de salvaguarda que deveria abranger identificação, proteção, conservação, restauração, reabilitação e manutenção de sítios históricos" (Rubino, 2008, p. 148).

Nas ultimas décadas, esses processos têm incorporado a "cultura" como conteúdo diferenciador das várias experiências de revitalização. Assim, o patrimônio histórico, as tradições locais, a cultura popular e outros elementos transformaram-se em mercadoria altamente valorizada nos debates sobre revitalização, na busca de um diferencial naquilo que se acreditaria ser um mercado global de cidades (Botelho, 2006). O discurso sobre as práticas de conservação patrimoniais acabou sendo ressignificado e, assim, a preservação passou a ser pensada não para evitar o desaparecimento, mas para se conferir valor ao local, não pela ação de novas edificações, mas pelo agenciamento, por vezes cenográfico, das antigas (Rubino, 2009). Os projetos de revitalização urbana, então, foram diretamente relacionados à valorização e recuperação do patrimônio de valor histórico e cultural nas cidades.

Nos anos 1960 já se observava, nos centros das grandes cidades norteamericanas e em algumas metrópoles europeias, a reocupação do centro pelas camadas médias. Em 1963, em Introduction to London: aspects of change, Ruth Glass usou o termo gentrificação para se referir à "invasão", pela classe média, aos bairros operários londrinos, transformando as modestas casas dos então moradores em elegantes residências, além de recuperar as antigas casas vitorianas. ${ }^{16}$ Em seguida o termo passou a ser utilizado para descrever processos de requalificação de centros históricos de grandes cidades. Se no inicio o processo foi conduzido pelo mercado imobiliário, ao longo do tempo transformou-se em uma política urbana, uma estratégia articulada e global que incorporou o discurso de city marketing, ou seja, a cidade como mercadoria global, capaz de atrair fluxos de capital que garantissem sua sobrevivência e crescimento (Botelho, 2005 e 2006).

\footnotetext{
${ }^{16}$ Ver, entre outros, Smith (2006).
} 
Nas políticas de gentrificação a prática do consumo é incorporada à tradição a partir de dois eixos. De um lado o centro histórico é representado como lugar de convergência da população para um suposto passado e identidades comuns, expressão de uma memória da nação, da tradição e da cidadania; por outro lado, a intervenção é representada como uma forma de recuperar um espaço urbano como público e de lazer, entretenimento e consumo da população (Leite, 2004).

$\mathrm{O}$ que se percebe nesses projetos contemporâneos de gentrificação é que, se no discurso, propõe-se a recuperação dos edifícios e das ruas, no sentido de devolver à população um espaço heterogêneo de sociabilidade, na prática o que se vê é a “expulsão", simbólica ou não, do vernacular (para falar com Zukin, 2000). Esses projetos partem de uma concepção de mercado que implica uma gestão mista entre Estado e iniciativa privada na forma de intervir no patrimônio como mercadoria cultural, cuja lógica altera o sentido do lugar ao tomar o cidadão como consumidor, identificado pelo seu poder aquisitivo. Essa prática é, obviamente, segregatória. Como afirma Smith (2006, p. 73):

A gentrificação produz agora paisagens urbanas que as classes médias e médias altas podem 'consumir' - uma vez que os sem teto foram rapidamente evacuados - e que contribuem para a formação de identidades de classe através de um espectro de classes significativo, ainda que de maneiras muito diferenciadas.

\section{O caso de Belo Horizonte}

Como foi dito na introdução, nossa hipótese é que em Belo Horizonte os processos de intervenção dos espaços públicos centrais parecem ter se estabelecido em uma direção diferente da chamada gentrificação. Não há como negar, por um lado, essa busca de embelezamento e mesmo higienização em alguns casos em Belo Horizonte, mas, por outro lado, e agora que muitas das intervenções já estão concluídas, é possível perceber que esse processo alterou a paisagem urbana do centro histórico da cidade sem, contudo, provocar grandes transformações no modo de vida de seus usuários. Talvez esses processos não tenham sido pensados unicamente como intervenções voltadas para o mercado, o entretenimento e o consumo cultural. Seja porque Belo Horizonte não é uma cidade turística, seja porque esses projetos tenham sido realizados aqui já nos anos 2000, seja porque a cidade é administrada por uma coligação de esquerda desde 2002. Para Corina Moreira (2008), as políticas de revitalização em Belo Horizonte parecem voltar-se para um público interno, distanciando-se, de algum modo, de uma competição entre as cidades frente 
às demandas do mundo globalizado. Desse modo, os projetos teriam como objetivo a solução de questões locais, estabelecendo uma relação direta com o público afetado.

Andrade e Jayme (2011) colocam que o programa Centro Vivo enfatiza o valor dos espaços públicos e o centro como "um local de todos". Para as autoras, mesmo que esse seja o discurso da maior parte dos programas de revitalização, em Belo Horizonte, pelo menos por enquanto, o Centro Vivo tem seguido essas diretrizes. É claro que não sem conflitos no uso dos espaços - e também não sem ambiguidades - tanto com o poder público, como entre os usuários, mas o conflito é da própria natureza dos espaços públicos.

Moreira (2008) pontua, contudo, que embora a lógica da intervenção não pareça pautada pela associação estrita entre consumo e cultura, mas pela preocupação com aqueles que convivem cotidianamente com a cidade, não significa que exclusões não venham ocorrendo ou que não se possa notar o que Leite (2004) chama de contrauso, ou seja, uma apropriação capaz não apenas de subverter os usos esperados de um espaço planejado e regulado, como também de possibilitar que esse espaço se transforme a ponto de dar origem a diferentes lugares, a partir da demarcação socioespacial da diferença e das ressignificações que esses contrausos realizam.

Um dos subprojetos do Programa Centro Vivo, lançado em 2007, pela Prefeitura, foi o Plano de Reabilitação do Hipercentro de Belo Horizonte. Esse documento, elaborado com a participação de técnicos da Prefeitura e de representantes da sociedade, apresentou diretrizes de ocupação e utilização para essa região da cidade, englobando soluções de planejamento, desenho urbano e paisagismo. Como grande parte dos projetos de revitalização urbana concebidos na ultima década, e das ações e diretrizes, coordenadas pelo Projeto Centro Vivo e pelo Plano de Reabilitação do Hipercentro já foram implementadas, é possível analisar esse processo.

Moreira (2008, p. 87) relata que durante sua pesquisa constatou um "tratamento diferenciado dado aos diversos grupos que compõem esse mosaico um tanto indefinido chamado comunidade", apontando para um diálogo privilegiado com comerciantes e moradores, mas excluindo, de modo geral, as pessoas que trabalham no centro da cidade. Os planos e projetos também não fazem referência às prostitutas que exercem suas atividades na região, fato que chama a atenção levando-se em consideração que a área de abrangência de suas atividades está inserida nos limites dos planos.

Ao discutir sobre o bairro da Luz, em São Paulo, Frúgoli Jr. e Sclair (2009) também explicitam sua dificuldade em definir aquele contexto sob a ótica da gentrificação. Se há o uso pelos extratos mais altos dos “equipamentos 
culturais", como a Pinacoteca e a Sala São Paulo, tal frequência é pontual e circunstancial e, mais importante, “... isso não configura, a princípio, uma mudança na vida pública do bairro em questão" (Frúgli Jr.; Sclair, 2009, p. 11). Os frequentadores desses espaços, aliás, não têm qualquer necessidade de interagir com o entorno, onde estão os moradores dos cortiços, os profissionais do sexo, os nóia. ${ }^{17}$

No caso da região central de Belo Horizonte pode ser possível também ir a um evento na Serraria Souza Pinto ou no Museu de Artes e Ofícios sem interagir com esses diferentes "outros", embora seja muito difícil não ver alguns deles, como os moradores de rua ou os usuários de drogas.

\section{Novas dinâmicas urbanas: consolidando o caráter cultural}

O Baixo Centro de Belo Horizonte, cenário de intervenções físicas recentes ancoradas no passado, experimenta, nos últimos anos, uma apropriação diferente e renovada, compartilhada com os usos tradicionais da região. Se a origem dessa movimentação pode não ser identificada com facilidade, a intensa utilização e apropriação dos espaços dessa área - que não estavam previstas na intervenção original - ligada, principalmente, a manifestações culturais diversas, permitem colocar em questão as discussões que apontam para o declínio do espaço público.

Algumas pesquisas empíricas sobre a convivência nos espaços públicos das grandes cidades compartilham essa ideia, revelando realidades mais complexas, que apontam, por um lado, para significativas mudanças nas formas de usufruir e interagir nos espaços públicos, mas afirmam, por outro lado, que muitos desses espaços mantêm grande vitalidade (Andrade; Jayme; Almeida, 2009; Girão, 2011).

Nosso objetivo aqui é refletir sobre a forma como vem se dando a construção social e a dinâmica presentes no Baixo Centro - que incorpora também alguns estabelecimentos particulares -, a representação e a significação dessa região para os grupos sociais que dele se apropriaram e se há algum papel das ações de revitalização urbana ali realizadas frente às novas formas de apropriação.

Como afirma Leite (2004), se as transformações urbanas raramente resultam de um desenvolvimento imanente da cidade, o oposto também parece verdadeiro: nenhuma cidade excessivamente planejada e controlada segue invariavelmente o modelo que a gerou. Principalmente como produto cultural, a cidade é sempre o resultado convergente de distintas influências formais e cotidianas. Essa afirmação é pertinente para nossa reflexão.

\footnotetext{
${ }^{17}$ Termo nativo usado para se referir aos usuários de crack (Frúgoli Jr; Sclair (2009)).
} 
O primeiro edifício histórico restaurado e com uma nova proposta de uso nessa região foi a Serraria Souza Pinto, em 1997. Desde então, seguiramse inúmeros esforços na tentativa de requalificação da área. Recentemente, esse espaço ganhou força e visibilidade, não necessariamente seguindo à risca as propostas contidas nos projetos originais implantados, mas de algum modo, podendo ser vistos como uma negação à visão dos planejadores do espaço urbano. Se algumas das apropriações e manifestações populares que ocorrem ali podem ser vistas como contrausos, nos termos de Leite (2002), é Jeudy (2005, p. 21) quem oferece uma pista para o relativo "sucesso" da região ao afirmar que "com as operações de urbanismo realizadas, os projetos de arquitetura concretizados se transformam, em um período relativamente curto, em expressões de uma urbanidade integrada".

Um dos primeiros movimentos a marcar a nova apropriação desse espaço é o Duelo de MCs, ${ }^{18}$ que acontece nas noites de sexta feira desde 2007, num duelo de improvisação aberto a quem quiser participar, ou somente assistir, e que reúne dezenas de pessoas debaixo do Viaduto de Santa Teresa, no espaço projetado para ser palco, pista de dança e arquibancada. Quando se estabeleceu no local, o Duelo reunia basicamente jovens pertencentes aos movimentos hip hop, com apresentação de b-boys, ${ }^{19}$ de DJs, ${ }^{20}$ grafiteiros e músicos. Atualmente, incorporou, além do público original, pessoas de classe média, artistas, estudantes universitários, entre outros, que participam da festa, ainda que mais como espectadores.

A identificação dos participantes do grupo original, que mantém presença regular na festa, é imediata. É possível, inclusive, pensar aquele local, sob o Viaduto de Santa Teresa, onde acontece o Duelo como um pedaço, no sentido de Magnani (2002), onde os frequentadores não necessariamente se conhecem, mas se reconhecem como portadores dos mesmos símbolos que remetem a gostos, orientações, valores e modos de vida semelhantes, com códigos de reconhecimento e comunicação bastante claros.

O duelo acontece semanalmente, embora a partir de uma negociação muitas vezes conflituosa com a Prefeitura, que concede o alvará para o evento, mas com a validade de apenas uma semana. $\mathrm{O}$ grupo, mesmo assim, insiste e "briga" para realização do evento. Por outro lado, um fato curioso é que a festa se desenrola sob o olhar da Polícia Militar, que, numa espécie de contrauso às avessas, ocupou a construção destinada à instalação de um bar, sob o Viaduto.

\footnotetext{
${ }^{18} \mathrm{MC}$ ou mestre de cerimônia do movimento hip hop, geralmente é um cantor e compositor que compõe e canta suas composições originais.

19 Dançarinos de dança de rua pertencentes ao movimento hip hop.

${ }^{20} \mathrm{DJ}$ ou disc jockey é o que seleciona e coloca para tocar as musicas.
} 
A Praça da Estação ${ }^{21}$ sempre abrigou manifestações culturais diversas e de grande porte. Quando a área foi reformulada, em 2007, o projeto previa, inclusive, uma melhor adequação do espaço para recebimento dessas manifestações. Contudo, em dezembro de 2009, o prefeito de Belo Horizonte decretou a proibição de utilização da Praça da Estação e anunciou que faria uma licitação para seleção de propostas e fixação de taxas para sua utilização.

A medida provocou uma reação imediata em uma parcela da população que lançou o movimento: Praia da Estação - a praça é nossa. O convite divulgado pela internet dizia:

DECRETO N ${ }^{\circ}$ 13.798 DE 09 DE DEZEMBRO DE 2009 do nosso digníssimo prefeito de Belo Horizonte, Marcio Lacerda, proíbe que aconteça qualquer tipo de evento na Praça da Estação. A pergunta permanece: a quem interessa que os espaços públicos sejam apenas pontos de passagem e consumo?

Se nos é negado o direito de permanecer em qualquer espaço público da cidade, ocuparemos esses espaços de maneira divertida, lúdica e aparentemente despretensiosa. Traga sua roupa de banho (bermuda, calção, biquíni, maiô, cueca), bóias, cadeiras, toalhas de praia, guarda-sol, cangas, farofa e a vitrolinha...

Traga tambores e viola! Traga comida para um banquete coletivo! Onde? Praça da Estação - Hipercentro de Belo Horizonte. Quando? Sábado, 16/01/2010, 09h30min. Quanto? De graça!

Ao longo de 2010 a Praia da Estação acontecia todos os sábados de manhã. Atualmente o evento não é realizado com a mesma regularidade, mas, em contextos específicos ainda acontece e mobiliza músicos, arquitetos, artistas plásticos, estudantes universitários, entre outros, que se reúnem para tomar "banho de praia" nas fontes da Praça. Desde então, o debate sobre a apropriação da cidade está na agenda de diferentes grupos e pessoas. Um exemplo é A Juventude Okupa a Cidade?, evento que teve início em 2011.22

A Rua Aarão Reis, que liga o Viaduto de Santa Teresa à Praça Rui Barbosa foi reformulada para abrigar um grande ponto de parada de transporte coletivo da região metropolitana. Durante o dia, é imenso o fluxo de pedestres e usuários de transporte coletivo que permanecem no local, esperando o seu ônibus, fazendo compras, lanchando ou consumindo bebidas alcoólicas nas lanchonetes e bares da rua. Durante a noite, diferentemente, a rua permanecia

\footnotetext{
${ }^{21}$ Praça Rui Barbosa.

${ }^{22}$ O Okupa é promovido pelo Observatório da Juventude da UFMG (Universidade Federal de Minas Gerais), em parceria com grupos de jovens de Belo Horizonte, cuja proposta é debater sobre a apropriação dos espaços públicos. Em 2011 foram realizados dois debates com a presença de representantes do Duelo de MCs, da Praia da Estação, das Brigadas Populares, além de professores universitários. Está marcado para o dia 13 de abril de 2012 a terceira edição.
} 
praticamente deserta, à exceção das noites de eventos na Serraria Souza Pinto, quando havia grande movimento de veículos.

Hoje esse cenário noturno está bastante modificado pela presença do Nelson Bordello, bar que se instalou no local, em abril de 2010:

Numa esquina fica a Praça da Estação, na outra a Serraria Souza Pinto. Logo em frente, está o Viaduto Santa Tereza. Abaixo deste, o palco em que MC's realizam duelos de rap e jovens organizam o movimento Praia da Estação, fazendo da rua Aarão Reis o endereço preferencial da arte urbana belorizontina. Em meio a esse cenário efervescente da revitalizada região central da capital, no número 554 da mencionada rua, está o bar, restaurante e cabaré Nelson Bordello. Trata-se de um espaço de experimentações artísticas, gastronômicas e comportamentais, que homenageia os bordeis da antiga zona boêmia na rua Guaicurus, como o famoso Montanhês comandado pela lendária Hilda Furacão. A programação, sempre diversificada, traz novidades de terça-feira a domingo. Tem para todos os gostos. ${ }^{23}$

O bar abre às onze horas da noite e fecha com a saída do último cliente, em geral já de manhã. Como tem uma área muito pequena, é possível transitar entre o lado de fora (a rua) e o lado de dentro do bar, o que provoca uma aglomeração enorme de pessoas na calçada da Rua Aarão Reis. Dependendo da programação, o público muda e há uma heterogeneidade entre os frequentadores. Segundo uma das sócias: “O Bordello se orgulha de misturar as pessoas do centro, que frequentam o centro, às pessoas da zona sul." Ela afirma que o público do bar é muito "misturado": "Teve um dia, durante a tarde, que um motorista de ônibus que faz ponto aqui em frente, desceu e veio aqui conversar comigo, ele queria saber o horário de funcionamento, porque ia entrar de férias e queria vir, disse que ele via uma galera bacana aqui”.

O Espaço CentoeQuatro também tem sido responsável por uma animação noturna permanente na área. Contendo um café com restaurante, faz parte da sua programação rotineira apresentações de grupos de jazz, de cantores, espetáculos teatrais e exposições. O local abriga ainda festas e shows especiais, geralmente articulados com outras programações culturais da cidade, como o Festival Mundial de Circo e o Festival Internacional de Teatro, entre outros.

Nos sábados à noite, desde outubro de 2010, a Gafieira CentoeQuatro leva, regularmente, centenas de pessoas ao local para um baile, com música ao vivo, dançarinos com a tradicional dança do picote. ${ }^{24}$ Dependendo do horário

${ }^{23}<$ www.nelsonbordello.com.br>.

${ }^{24}$ Ao entrar no local, os frequentadores recebem uma cartela que será apresentada ao dançarino no momento da dança, que picota a cartela no fim. A cada dança, um novo picote. O valor total será pago ao final, juntamente com os demais consumos. O valor de cada picote, atualmente, é de dois reais. 
em que se chega ao baile (que começa às nove horas da noite) espera-se por até duas horas na fila de entrada.

Desde 2011, o Grupo Espanca de teatro instalou, ao lado do Nelson Bordello sua sede.

Há cerca de um ano foi criado o time de futebol feminino, Baixo Bahia Futebol Social, que parece ter sido criado a partir de duas motivações: o interesse de algumas garotas pelo futebol e um ato político de ocupação de espaços públicos, com vistas a interagir com o vernacular. $\mathrm{O}$ time treina uma vez por semana, debaixo do Viaduto de Santa Teresa.

Fazendo parte do mesmo complexo, o Museu de Artes e Ofícios também oferece uma programação cultural regular que inclui debates com escritores e shows musicais, além de suas exposições regulares.

Também nas imediações está a Zona Grande. O quadrilátero formado pelas ruas Guaicurus, Caetés, São Paulo e Rio de Janeiro, que sempre conteve em Belo Horizonte a chamada "zona de baixo meretrício" ou "zona grande". Hoje, cerca de 15 pequenos hotéis ${ }^{25}$ (este número flutua devido ao frequente fechamento e abertura de novos estabelecimentos) funcionam na região, abrigando mais de mil mulheres que atendem os clientes durante todo o dia. Nestes hotéis a mulher paga uma diária fixa, que pode ser por um ou dois turnos, de oito horas cada ( $09 \mathrm{~h} 00 \mathrm{~min}$ às $16 \mathrm{~h} 00 \mathrm{~min}$ e $16 \mathrm{~h} 00 \mathrm{~min}$ às $22 \mathrm{~h} 00 \mathrm{~min})$, ou pelo dia todo para ocupar um quarto onde recebe seus clientes (a diária/ turno varia, dependendo do hotel, de 10 à 25 reais). O preço do programa é resultado da negociação da profissional com o cliente, levando em conta os serviços a serem prestados. A mulher atende quantos clientes quiser ou necessitar. É certo que enquanto elas estão trabalhando nos hotéis o Nelson Bordello ainda está fechado e a Gafieira do Espaço CentoeQuatro começa apenas uma hora antes do hotéis fecharem.

\section{Concluindo}

Este texto oferece, de forma muito sucinta, uma visão da multiplicidade de atividades culturais que vem se instalando no Centro de Belo Horizonte, mobilizando um grande número de pessoas para esse local e, pelo que temos observado, se por um lado, muitos dos frequentadores dessa noite no Centro de Belo Horizonte estejam ali apenas para se divertir, há, por outro lado, grupos que buscam revelar o sentido político nessa frequência que não se resume aos bares e bailes. Esses grupos vão também aos eventos da Praia e aos debates

\footnotetext{
${ }_{25}$ Aurora, Brilhante, Catete, Diamante, Imperial, Lírio, Magnífico, Maravilhoso, Mirage, Novo América, Pensão Mineira, Privé, Requinte, Stylus e Veredas.
} 
do Okupa. Pelo que se nota, parece tratar-se de uma atitude que, ao valorizar o centro, parece se colocar em um lugar de oposição a determinado tipo de lazer e de cultura segregacionista, como a que ocorre nos shopping centers e em outros espaços elitizados e situados nas áreas também elitizadas da cidade. Enfim, mesmo que não se possa falar exatamente em uma integração entre diferentes estratos, o Centro de Belo Horizonte vem sendo também apropriado por grupos de classe média e grupos culturais que o valorizam na sua diversidade.

Por fim, mas não menos importante, aqui não é exatamente um espaço de conclusão, mas talvez de lançar questões para a continuidade da investigação: quais são as formas de apropriação e que representações a população que frequenta e transita pela região faz desse local, objeto de inúmeros projetos de revitalização urbana? A movimentação constante de pessoas na área, marcada durante o dia pela circulação de pedestres e de veículos, aliada à movimentação noturna, voltada principalmente às atividades culturais parece indicar que a população vem apropriando-se de forma intensa dessa região. Mas fica ainda uma pergunta: será que as intervenções urbanas implantadas, ainda que não tenham sido apropriadas da forma original como foram propostas, contribuem com essa apropriação?

\section{Referências}

ANDRADE, Carlos Drummond de. Boitempo II. Rio de Janeiro: Record, 1987.

ANDRADE, Luciana Teixeira de; JAYME, Juliana Gonzaga. Centro e Periferia: refletindo sobre seus significados no contexto contemporâneo de grandes cidades. Trabalho apresentado na IX Reunião de Antropologia do Mercosul, Curitiba, 2011 (mimeo).

ANDRADE, Luciana Teixeira de; JAYME, Juliana Gonzaga; ALMEIDA, Rachel de Castro. Espaços públicos: novas sociabilidades, novos controles. Cadernos Metrópole, São Paulo, n. 21, p. 131-151, primeiro semestre de 2009.

ARANTES, Antônio Augusto. Patrimônio Cultural e cidade. In: FORTUNA, C.; LEITE, R. P. (Orgs.). Plural de Cidades: novos léxicos urbanos. Coimbra: Edições Almedina, 2009.

ARROYO, Michele Abreu. Reabilitação urbana integrada e a centralidade da Praça da Estação. Dissertação (Mestrado em Ciências Sociais) - Pontifícia Universidade Católica de Minas Gerais, Belo Horizonte, 2004.

BENJAMIN, Walter. Paris, capital do século XIX. In: KOTHE, Flávio (Org.). Walter Benjamin. São Paulo: Ática, 1985.

BARREIRA, Irlys Alencar. Pulsações no Coração da Cidade: cenários de intervenção em centros urbanos contemporâneos. Cadernos CRH, Salvador, v. 23, n. 59, maio-ago. 2010 . 
BOTELHO, Tarcísio Rodrigues. Revitalização de centros urbanos no Brasil: uma análise comparativa das experiências de Vitória, Fortaleza e São Luis. Revista Eure, Santiago do Chile, v. XXXI, n. 93, p. 53-71, ago. 2005. Disponível em: <www.scielo. cl/pdf/eure/v31n93/art04.pdf>. Acesso em: 15 fev. 2010.

BOTELHO, Tarcísio Rodrigues. A revitalização da região central de Fortaleza (CE): novos usos dos espaços públicos da cidade. In: FRUGOLI JR., Heitor; ANDRADE, Luciana Teixeira de; PEIXOTO, Fernanda Arêas (Orgs.). As cidades e seus agentes: práticas e representações. Belo Horizonte: Pucminas/Edusp, 2006.

CERTEAU, Michel; GIARD, Luce. Entremeio. In: CERTEAU, Michel. A invenção do cotidiano (morar, cozinhar). 5. ed. Petrópolis: Vozes, 2003.

CRIEKINGEN, Mathieu van. A cidade renasce: formas, políticas e impactos de revitalização residencial em Bruxelas. In: BIDOU-ZACHARIASEN, Catherine. De volta à cidade: dos processos de gentrificação às políticas de 'revitalização' dos centros urbanos. São Paulo: Annablume, 2006.

DUARTE, Ronaldo Goulart. O processo de reabilitação e renovação urbana na cidade do Rio de Janeiro e suas perspectivas. Scripta Nova - Revista electronica de geografia y ciencias sociales,. Universidad de Barcelona, v. IX, n. 199(44), ago. 2005. Disponivel em: <http://www.ub.edu/geocrit/sn/sn-199-44.htm>. Acesso em: 15 jan. 2011.

FRÚGLI JR., Heitor; SCLAIR, Jéssica. O bairro da Luz em São Paulo: questões antropológicas sobre o fenômeno da gentrification. Cuadernos de Antropología Social, UBA, n. 30, 2009.

GIRÃO, Adriana. Para animar os ânimos: interações, sentidos e percepções do centro de uma grande cidade a partir de suas sonoridades comerciais. Dissertação(Mestrado em Ciências Sociais) - Pontifícia Universidade Católica de Minas, Belo Horizonte, 2011.

JEUDY, Henri-Pierre. Espelho das cidades. Rio de Janeiro: Casa da Palavra, 2005.

LEITE, Rogério Proença. Contra-usos da cidade. Lugares e espaço público na experiência urbana contemporânea. Campinas, SP: Editora da Unicamp; Aracaju: Editora da UFS, 2004.

LEITE, Rogério Proença. Contra-usos e espaço público: notas sobre a construção social dos lugares na Manguetown. Revista Brasileira de Ciências Sociais, São Paulo, v. 17, n. 49, p. 115-172, jun. 2002.

LEMOS, Celina Borges. Antigas e novas centralidades: a experiência da cultura do consumo no centro tradicional de Belo Horizonte. Belo Horizonte: Editora da Escola de Arquitetura da UFMG, 2010.

MAGNANI, José Guilherme Cantor. A Antropologia Urbana e os desafios da metrópole. 2003. Disponível em: <http://www.nau.org/AntropologiaUrbanadesafiosmetropole. html>. Acesso em: 30 set. 2010.

MAGNANI, José Guilherme Cantor. De perto e de dentro: notas para uma etnografia urbana. Revista Brasileira de Ciências Sociais, São Paulo, v. 17, n. 49, jun. 2002. Disponível em: <http://www.scielo.br/pdf/rbcsoc/v17n49/a02v1749.pdf >. Acesso em: 10 set. 2010. 
MOREIRA, Corina Maria Rodrigues. Patrimônio cultural e revitalização urbana. Usos, apropriações e representações da Rua dos Caetés. 2008. Dissertação (Mestrado em Ciências Sociais) - Pontifícia Universidade Católica de Minas Gerais, Belo Horizonte, 2008.

PRÁXIS Projetos e Consultoria Ltda. Plano de reabilitação do Hipercentro de Belo Horizonte. Belo Horizonte: PBH, 2007.

RIVIÈRE D'ARC, Hélène. Requalificar o século XX: projeto para o centro de São Paulo. In: BIDOU-ZACHARIASEN, Catherine. De volta à cidade: dos processos de gentrificação às políticas de 'revitalização' dos centros urbanos. São Paulo: Annablume, 2006.

RUBINO, Silvana. Enobrecimento Urbano. In: FORTUNA, C.; LEITE, R. P. (Orgs.). Plural de Cidades: novos léxicos urbanos. Coimbra: Edições Almedina, 2009.

RUBINO, Silvana. Nem findas nem lindas: cidades e gestão da memória. In: LEITE, Rogério Proença (Org.). Cultura e vida urbana. Ensaios sobre a cidade. São Cristóvão. UFS, 2008. p. 142-169.

SMITH, Neil. A gentrificação generalizada: de uma anomalia local à 'regeneração' urbana como estratégia urbana global. In BIDOU-ZACHARIASEN, Catherine. De volta à cidade: dos processos de gentrificação às políticas de 'revitalização' dos centros urbanos. São Paulo: Annablume, 2006.

ZUKIN, Sharon. Paisagens Urbanas pós-modernas: mapeando cultura e poder. In: ARANTES, A. A. (Org.). O espaço da diferença. Campinas: Papirus, 2000. 